\title{
Ethics education and deliberation
}

\author{
Henk ten Have ${ }^{1}$
}

Published online: 28 June 2016

C) Springer International Publishing AG 2016

In May 2016, the U.S. Presidential Commission for the Study of Bioethical Issues presented its last report to President Obama. During its tenure the Commission had published 10 reports on a range of issues: synthetic biology; sexually transmitted infection experiments in Guatamala; whole genome sequencing; neuroscience research; human subjects research; and ethics and ebola. This last report Bioethics for Every Generation is different. It focuses on democratic deliberation and ethics education, as well as their interconnections. At the same time, this Presidential Commission has made a huge effort to promote ethics education during its tenure. Diverse and helpful pedagogical materials have been developed, such as user guides, primers, teacher tools, and videos. Modules on informed consent, privacy, and vulnerable populations can be found when visiting the Commission's website (www.bioethics.gov).

In its last report, the Commission argues that we are all participants in our democracy and responsible members of our world. This is the overall background of ethics education. This requires deliberation and understanding of values. Education is required not only to facilitate deliberation but also to better understand values, our own and those of others. Furthermore, given the challenges of science and technology, it will contribute fundamentally to reasoned decision-making in our pluralistic societies. This background also requires "the infusion of bioethics training throughout education." (page 3). The Commission has three recommendations. First, broad-based ethics education should start early and should be ongoing through education at different stages of life, building ethics literacy. Second, bioethics training and education should particularly be developed at graduate and professional levels; the aims should be "to foster character development, cultivate a culture of responsibility" (page 8). Third, promote teacher training programs. Finally, the report elaborates the connections between deliberation and education. Education is not primarily for jobs or economic growth; it is crucially important for democratic citizenship. It nurtures public discourse

Henk ten Have

tenhaveh@duq.edu

1 McAnulty College and Graduate School of Liberal Arts, Center for Healthcare Ethics, Duquesne University, Fisher Hall 300, 600 Forbes Avenue, Pittsburgh, PA 15282, USA 
and civic engagement for the common good, constituting what makes a society rather than a business or a church a place of human flourishing.

The idea of life-long bioethics education is exemplified in this second issue of the journal by Susana Vidal (2016). Working for the UNESCO Bioethics Program in Latin America and the Caribbean she has set up various educational activities in the region. One is the successful initiative of the Lifelong Education Program in Bioethics, started 10 years ago. In her contribution, Vidal clearly describes this program and its accomplishments. But, more importantly, she explains the 'background philosophy' of the program, especially in a changing context in an important part of the developing and globalizing world. There is not only a need for new educational programs; there is a need for different and critical programs that can properly address the new challenges within a context that continues to articulate inequality, injustice and exploitation in various forms. This context requires a specific educational methodology that encourages critical learning. It also certainly requires deliberation.

The changed context of present-day education not only affects bioethics teaching but also environmental ethics education, as José Roque Junges (2016) demonstrates in his contribution. Biodiversity loss, climate change, and environmental degradation do not first of all call for scientific and technological solutions. They challenge human values. The consequence is, as Junges puts it: "we must relearn how to understand nature as our common home." This should be done by education. But again, this is not merely a matter of knowledge and information. It should emphasize ethical awareness, critical reflection, and action. That message is repeated several times in this issue.

\section{References}

Junges, José Roque. 2016. What is the future of ethics teaching in the environmental sciences. International Journal of Ethics Education 1(2): in this issue.

Presidential Commission for the Study of Bioethical Issues. 2016. Bioethics for every generation. Deliberation and education in health, science, and technology. Washington, D.C. (http://www.bioethics.gov).

Vidal, Susana. 2016. Lifelong learning in bioethics and human rights: 10 years of the bioethics lifelong education programme in LAC. International Journal of Ethics Education 1(2): in this issue. 